\title{
Real-World Impact of a Decision Support Tool on Colony-Stimulating Factor Use and Chemotherapy-Induced Febrile Neutropenia Among Patients With Breast Cancer
}

\author{
Abiy Agiro, $\mathrm{PhD}^{\mathrm{a}}$; Andrea DeVries, $\mathrm{PhD}^{\mathrm{a}}$; Jennifer Malin, $\mathrm{MD}, \mathrm{PhD}^{\mathrm{b}}$; and Michael J. Fisch, MD, $\mathrm{MPH}^{\mathrm{c}}$
}

\begin{abstract}
Background: White blood cell colony-stimulating factors (CSFs) decrease the incidence of chemotherapy-induced febrile neutropenia (FN). Widespread use of CSFs that is not guideline-concordant has been reported. Among patients with breast cancer receiving chemotherapy, the ability of evidence-based decision support tools to promote risk-appropriate reductions in CSF use without increased incidence of FN has not been examined. Methods: A retrospective cohort design and US commercial claims data were used. The impact of CSF decision support was analyzed among women with breast cancer receiving first-cycle chemotherapy from April 1, 2013, to March 30, 2015. The tool was implemented as part of a prior authorization process in 9 states starting July 1, 2014. Patients were assigned to intervention (ie, states where the decision support tool had been implemented) or nonintervention states (ie, 39 states where the tool had not been implemented). CSF use and subsequent incidence of FN were compared using difference-in-difference (DID) regressions adjusting for baseline differences in FN risk factors such as comorbidities and various infections. Results: The study sample of 7,224 patients (intervention states: pre-implementation, 1,991 and post-implementation, 2,010; nonintervention states: pre-implementation, 1,569 and post-implementation, $1,654)$ showed no significant difference in risk factors. Before and after implementation, a significant decrease in the proportion of patients with CSF use was observed in the intervention states (75\% to $69 \%$ ) compared with no significant change in the nonintervention ( $72 \%$ to $71 \%$ ) states (DID, $-5.4 \% ; 95 \% \mathrm{Cl},-6.0 \%$ to $-4.7 \% ; P=.006)$. No significance increase in FN incidence occurred in intervention ( $5.0 \%$ to $5.5 \%$ ) and nonintervention ( $5.4 \%$ to $4.8 \%$ ) states (DID, $0.2 \% ; 95 \% \mathrm{Cl},-0.20$ to $0.30 ; P=.78)$. Similar results were obtained in subgroups by comorbidities and in sensitivity analyses by claims-based FN definitions. Conclusions: CSF use decreased modestly after implementation of the decision support tool, with no observed changes in FN rates. Such tools can reduce practice variation to improve care standards.
\end{abstract}

J Natl Compr Canc Netw 2018;16(2):162-169 doi: 10.6004ljncen.2017.7033

Escalating expenditures on discretionary oncology treatments with little to no evidence of benefit (ie, overtreatment) have prompted stakeholders to propose various value frameworks to assess oncology treatments and care practices. Overtreatment is a major contributor to at least $20 \%$ of healthcare expenditures that may be classified as inefficient or wasteful. ${ }^{1-5}$ Most frameworks for value-based cancer care require an assessment

From ${ }^{2}$ HealthCore Inc., Wilmington, Delaware; bैAnthem, Inc., Woodland Hills, California; and 'AIM Specialty Health, Deerfield, Illinois.

Submitted April 20, 2017; accepted for publication September 8, 2017. Dr. Malin was an employee of Anthem, Inc. at the time of this study. Dr. Fisch is an employee of AIM Specialty Health, a wholly owned subsidiary of Anthem, Inc. Drs. Agiro, and DeVries are employees of HealthCore, a wholly owned subsidiary of Anthem, Inc. of real-world benefits, including improvement in care outcomes and adherence to evidence-based standards of care. $^{6}$

Recognizing that overtreatment is not without harm for patients with cancer receiving chemotherapy, the NCCN Clinical Practice Guidelines in Oncology (NCCN Guidelines) for Myeloid Growth Factors recommend febrile neutropenia (FN) prophylaxis using a

Funding for this study was provided by Anthem, Inc.

Author contributions: Study concept and design: Agiro, DeVries. Data acquisition: Agiro. Data analysis and interpretation: Agiro, DeVries, Malin, Fisch. Manuscript preparation: Agiro, DeVries, Malin, Fisch. Final approval of manuscript: Agiro, DeVries, Malin, Fisch.

Correspondence: Abiy Agiro, PhD, HealthCore, Inc., 123 Justison Street Suite 200, Wilmington, DE 19801. E-mail: aagiro@healthcore.com 
colony-stimulating factor (CSF) when risk, based on the chemotherapy regimen and patient risk factors, is "high" (>20\%). ${ }^{7}$ CSF prophylaxis may also be considered based on patient risk factors when the regimen-based FN risk is intermediate $(10 \%-20 \%) ., 9$ However, several studies have reported a high proportion of possibly discretionary administration of CSF, ${ }^{10-15}$ with some reporting CSF administration as high as 30\% among patients at low risk for FN. ${ }^{16-19}$ Specifically, for patients with breast cancer, as much as $50 \%$ of CSF administration was not aligned with national guidelines. ${ }^{16}$ Such findings suggest the need for additional interventions beyond the publication of clinical guidelines. ${ }^{20}$

One reason some CSF administrations do not align with guidelines stems from the challenges of incorporating patient risk factors alongside regimenbased FN risk stratifications. ${ }^{21}$ The decision to administer CSF is relatively straightforward for patients receiving chemotherapy regimens with a high risk of inducing $\mathrm{FN}$. For patients receiving intermediate-risk (FN risk $\geq 10 \%$ to $\leq 20 \%$ ) or low-risk (FN risk $<10 \%$ ) regimens, however, careful consideration must be given to patient-, disease-, and treatmentrelated factors.

As the heterogeneity of physician assessments on risk of FN persist in clinical practice, ${ }^{22}$ decision support tools are increasingly being implemented as part of prior authorization programs to address the challenges of incorporating multiple factors in oncology treatment decisions. Decision support tools have been reported to result in long-term improvements in practice variation. ${ }^{23-25}$ For example, adding a decision support tool to a national payer prior authorization program minimized denial rates (by approximately $1 \%$ ) while reducing chemotherapy drug cost trends by $20 \%{ }^{26}$; however, unintended patient outcomes or level of CSF administration were not assessed.

This study evaluated an evidence-based CSF decision support tool implemented by one national payer across 9 intervention states for patients with breast cancer. This tool was developed using NCCN and ASCO guidelines pertaining to myeloid growth factor use. We present differences in population-level changes in CSF administration between the intervention and nonintervention states. If the CSF decision support tool promoted appropriate $\mathrm{FN}$ risk stratification among patients with breast cancer, we hypothesized that there should be no change in population-level pre- and post-implementation FN incidence rates.

\section{Methods}

\section{Data Source}

This retrospective observational cohort study used claims data from the HealthCore Integrated Research Environment (HIRE). HIRE includes medical and pharmacy claims data for nearly 40 million commercially insured members geographically spread across the United States. This study was conducted in full compliance with relevant provisions of the Health Insurance Portability and Accountability Act (HIPAA). Researchers had access to only a limited data set that contained no patient identifiers, and no patients were contacted directly. The study was exempt from Institutional Review Board oversight under the provisions of Privacy Rule 45 CFR 164.514(e).

\section{Identification of Study Population}

The study population comprised commercially insured adult women (aged $\geq 18$ years) diagnosed with breast cancer (ICD-9-CM code 174) who initiated chemotherapy before (April 2013-December 2013) or after (July 2014-March 2015) implementation of the decision support tool to promote risk-appropriate CSF use. Receipt of chemotherapy was ascertained from medical claims using Healthcare Common Procedure Coding System (HCPCS) codes (see supplemental eTable 1, available with this article at JNCCN.org); the earliest chemotherapy date was defined as the index date if no claim for a chemotherapy agent was made in the first 6 months preceeding the index date (ie, limited to first cycle chemotherapy). All patients had continuous health plan eligibility in the 6 months prior to the index date. Patients were followed up to 6 months after the index date or until September 30, 2015, whichever occurred first.

\section{Study Group Classification}

We classified patients into 1 of 4 independent study groups (ie, a patient could only have one index date) in the intervention (pre- and post-implementation) and nonintervention states (pre- and post-implementation), respectively. Starting on July 1, 2014, the decision support program was implemented in phases; details of the rollout were previously de- 
Agiro et al

scribed. ${ }^{27}$ In the 9 intervention states (ie, California, Colorado, Georgia, Indiana, Kentucky, Missouri, Nevada, Ohio, and Wisconsin) where the decision support tool had been implemented, we identified 1,991 and 2,010 patients with breast cancer initiated on chemotherapy before and after implementation, respectively. In the nonintervention states (ie, 39 states where the decision support tool had not been implemented), we identified 1,569 and 1,654 patients with breast cancer initiated on chemotherapy before and after program implementation, respectively. Of the 4 study groups, the decision to administer CSF was guided by the decision support tool in only 1 group of patients: those in intervention states in the post-implementation period. In the remaining 3 study groups that served as controls, usual practice of post-service physician attestation was in effect.

\section{Description of the Intervention}

Through an online Web portal, the CSF decision support tool provides automated FN risk-appropriate recommendations for CSF use based on national guideline recommendations and available high-quality evidence (Figure 1). The tool provides a digital library of searchable treatment regimens from multiple guidelines and published sources (including but not limited to NCCN Guidelines and the NCCN Drugs $\&$ Biologics Compendium). Although the tool is based on high-quality evidence, including randomized controlled trials and widely accepted guidelines, the tool itself has not been validated. This real-time tool stratifies patients into 3 risk categories based on the
FN risk of the planned chemotherapy regimen: low $(<10 \%)$, intermediate $(10 \%-20 \%)$, or high $(>20 \%)$. A recommendation for or against CSF prophylaxis is made according to whether the FN risk of the planned chemotherapy regimen is $>20 \%$ or $<10 \%$. The recommendation for CSF prophylaxis is affirmative for regimens with an $\mathrm{FN}$ risk of $\geq 20 \%$, whereas the recommendation is not affirmative for regimens with an FN risk $<10 \%$. For planned regimens at intermediate FN risk, oncologists confirm the presence of individual patient-, disease-, and treatment-related factors through a series of questions. Affirmative responses to these questions result in a recommendation for CSF prophylaxis. The tool allows the addition of custom regimen requests, which are reviewed by a medical oncologist and followed with an authorization or a peer-to-peer discussion. Once obtained, CSF approval remains in effect for 6 months to cover the full course of chemotherapy treatment.

\section{Outcome Measures}

To assess the impact of the decision support tool on CSF support during chemotherapy, we examined the difference in population-level changes in CSF use (defined as the presence of any medical claim with HCPCS codes J1442, J1446, J2505, or J2820) within 6 months from chemotherapy initiation during the pre- and post-implementation periods between intervention and nonintervention states. Differences in $\mathrm{FN}$ incidence over a 6-month period after chemotherapy initiation between intervention and nonintervention states in the pre- and post-imple-

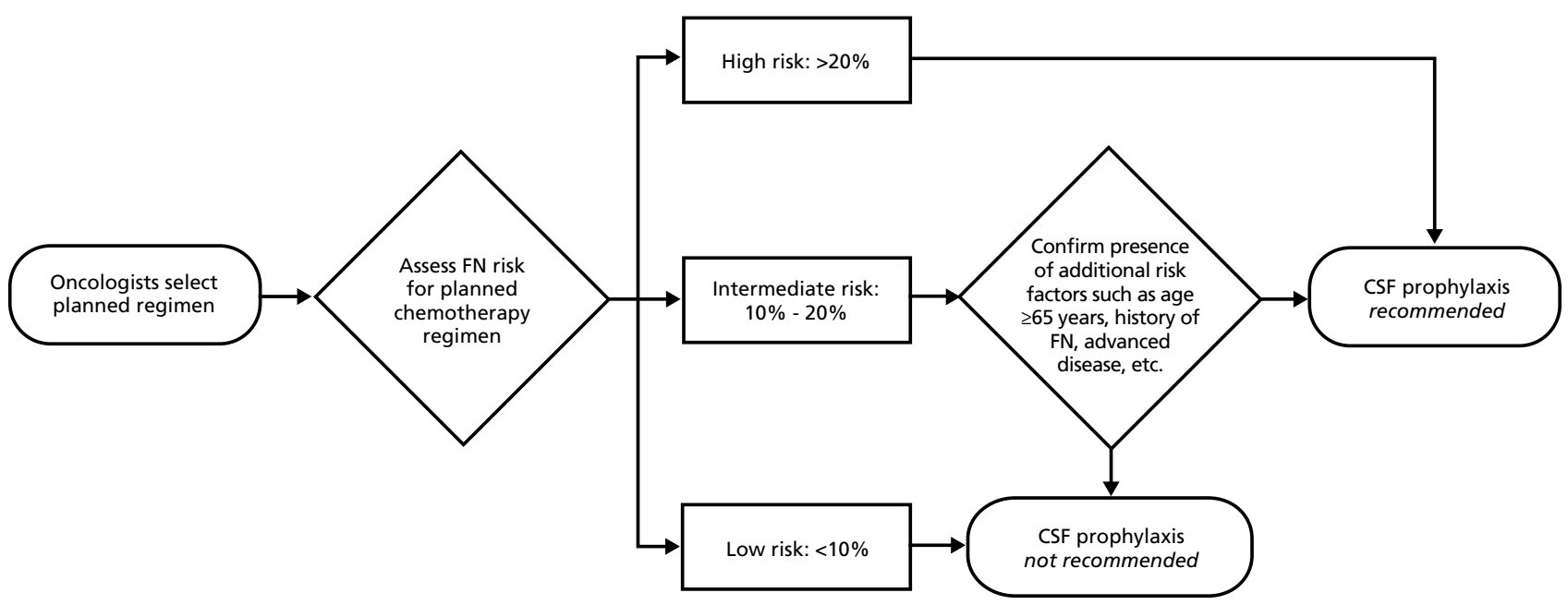

Figure 1. Febrile neutropenia (FN) risk-appropriate recommendations for colony-stimulating factor (CSF) use based on national guideline recommendations and available high-quality evidence. 
mentation periods were evaluated to determine any unintended impact of the CSF decision support tool on subsequent $\mathrm{FN}$ incidence.

We considered 3 operational definitions of FN. First, episodes of FN were identified by the presence of inpatient hospitalization or emergency department (ED) visit with an ICD-9 CM code for neutropenia (288.0) and fever (780.6) using previously validated claims-based algorithms (positive predictive value [PPV], 87\%; sensitivity, 34\%-57\%). ${ }^{28}$ A second broader (neutropenia and [fever or infection]) claimsbased FN definition and an even more comprehensive (neutropenia or fever or infection) definition (PPV, $35 \%$; sensitivity, $87 \%$ ) were used as sensitivity analyses (see supplemental eTable 2 for infection diagnosis code).${ }^{28}$ Lastly, we examined all-cause hospitalizations or ED visits to account for any remaining misclassification bias. We further explored the impact of the decision support tool in subgroups classified according to Charlson-Deyo comorbidity index ${ }^{29}$ (CDI) score (ie, 0 and $\geq 1$ comorbid conditions other than cancer). Sample size limitations prevented additional subgroup analyses, such as low-risk regimens.

\section{Baseline Characteristics}

Patient characteristics and the following potential risk factors for $\mathrm{FN}$ were assessed in the 6-month baseline period: age; geographic region of residence; health insurance exchange status; rural-urban status; comorbidity burden using a modified CDI for noncancer comorbidities; history of pancytopenia, neutropenia, anemia, bacterial infections, fungal infections, nonspecific infections, HIV, hepatitis B and $\mathrm{C}$ virus infections, fever, radiation therapy, or breast cancer surgery; presence of metastases; and lymph node involvement. Because FN risk varies by level of chemotherapy agent myelotoxicity (supplemental eTable 3 ), we examined the distribution of these agents before and after implementation. The agentlevel myelotoxicity risk rating was obtained from a recent publication. ${ }^{28}$ However, we did not aggregate the individual chemotherapy agents into regimens because we did not have a sufficient sample size to conduct a regimen-level analysis. Additionally, we assessed all-cause hospitalization and ED visits.

\section{Statistical Analysis}

We described baseline patient characteristics as means with standard deviations for continuous variables and proportions for categorical variables. To assess comparability between patients in the intervention and nonintervention states in concurrent periods, we compared baseline differences among patients using a $t$ test for continuous variables and a $\chi^{2}$ test for categorical variables. We used multivariable difference-in-differences models to examine study outcomes, assessed differences in trend changes in CSF administration rate and $\mathrm{FN}$ incidence, and used generalized estimating equations to account for clustering within intervention and nonintervention groups between the preand post-implementations periods, adjusting for age, modified CDI, geographic region of residence, history of bacterial infections, neutropenia, and nonspecific infections. Statistical analyses were conducted using SAS version 9.4 (SAS Institute Inc.; Cary, NC).

\section{Results}

\section{Patient Characteristics}

Overall, the mean patient age was 55.7 years, with those in intervention states slightly older than those in nonintervention states in both periods (mean, 57 and 55 years, respectively; Table 1). Patients in intervention states predominantly lived in the Northeastern and Southern United States. At least $77 \%$ of patients in both groups resided in urban areas. Patients in intervention and nonintervention states in both periods had relatively few comorbidities, with most ( $71 \%$ vs $70 \%$, respectively) having a modified CDI score of 0 . Approximately the same proportion of patients received chemotherapy agents with an intermediate/high-risk level for myelosuppression (Table 1 ) in the pre-implementation (90.7\% in both intervention and nonintervention states) and post-implementation periods ( $87.8 \%$ in intervention vs $88.0 \%$ in nonintervention states). No clinically meaningful differences were seen in other baseline characteristics. Individual-level distribution of patients receiving intermediate/ high-risk chemotherapy agents were mostly similar between intervention and nonintervention states (supplemental eTable 3).

\section{Impact on CSF Administration}

In intervention states, population-level CSF administration decreased from $74.9 \%$ pre-implementation to $68.5 \%$ post-implementation, an absolute difference of $6.4 \%$ (Table 2 ). In comparison, population- 
Agiro et al

Table 1. Patient Demographics and Clinical Characteristics for Patients Receiving Chemotherapy

\begin{tabular}{|c|c|c|c|c|c|c|}
\hline \multirow[b]{2}{*}{ Characteristic } & \multicolumn{2}{|c|}{$\begin{array}{l}\text { Intervention States } \\
\text { (Subject to the Tool) }\end{array}$} & \multicolumn{2}{|c|}{$\begin{array}{l}\text { Nonintervention States } \\
\text { (Not Subject to the Tool) }\end{array}$} & \multicolumn{2}{|c|}{ Baseline Comparison } \\
\hline & $\begin{array}{l}\text { Pre } \\
\text { n (\%) }\end{array}$ & $\begin{array}{l}\text { Post } \\
\text { n (\%) }\end{array}$ & $\begin{array}{l}\text { Pre } \\
\text { n (\%) }\end{array}$ & $\begin{array}{l}\text { Post } \\
\text { n (\%) }\end{array}$ & $\begin{array}{l}\text { Pre } \\
P \text { Value }\end{array}$ & $\begin{array}{l}\text { Post } \\
P \text { Value }\end{array}$ \\
\hline Total, N & 1,991 & 2,010 & 1,569 & 1,654 & & \\
\hline Mean age (SD), y & $57(11)$ & $56.3(11)$ & $55(11)$ & $54.4(11)$ & .001 & .001 \\
\hline $18-44$ & $287(14)$ & $285(14)$ & $252(16)$ & 309 (19) & & \\
\hline $45-64$ & $1,267(64)$ & $1,347(67)$ & $1,035(66)$ & 1,091 (66) & .010 & $<.001$ \\
\hline$\geq 65$ & $437(22)$ & $378(19)$ & $282(18)$ & $254(15)$ & & \\
\hline \multicolumn{7}{|l|}{ Region of residence } \\
\hline West & $1,088(55)$ & $555(28)$ & $74(5)$ & $144(9)$ & \multirow{4}{*}{$<.001$} & \multirow{4}{*}{$<.001$} \\
\hline Midwest & $593(30)$ & $829(41)$ & $137(9)$ & $172(10)$ & & \\
\hline South & $299(15)$ & $624(31)$ & $673(43)$ & $930(56)$ & & \\
\hline Northeast & $1(0)$ & $2(0)$ & $631(40)$ & $408(25)$ & & \\
\hline \multicolumn{7}{|l|}{$\begin{array}{l}\text { Health insurance exchange } \\
\text { identifier }\end{array}$} \\
\hline Nonexchange member & $1,970(99)$ & $1,815(90)$ & $1,569(100)$ & $1,562(94)$ & \multirow{2}{*}{$<.001$} & \multirow{2}{*}{$<.001$} \\
\hline Exchange member & $21(1)$ & $195(10)$ & $0(0)$ & $92(6)$ & & \\
\hline \multicolumn{7}{|l|}{ Geographic area } \\
\hline Urban & $1,641(83)$ & $1,532(77)$ & $1,232(82)$ & $1,320(80)$ & \multirow{2}{*}{.599} & \multirow{2}{*}{$<.001$} \\
\hline Rural/Isolated areas & $334(17)$ & $468(23)$ & $263(18)$ & $323(20)$ & & \\
\hline \multicolumn{7}{|l|}{ Clinical indicators ${ }^{a}$} \\
\hline \multicolumn{7}{|l|}{ Comorbidity burden } \\
\hline 0 & $1,422(71)$ & $1,362(68)$ & $1,094(70)$ & $1,165(70)$ & \multirow{3}{*}{.388} & \multirow{3}{*}{.058} \\
\hline 1 & $505(25)$ & $558(28)$ & $429(27)$ & $437(26)$ & & \\
\hline$\geq 2$ & $64(3)$ & $90(4)$ & $46(3)$ & $52(3)$ & & \\
\hline Cancer surgery & $1,214(61)$ & $1,068(53)$ & $1,011(64)$ & $917(55)$ & .034 & .163 \\
\hline Metastases & $547(28)$ & $567(28)$ & $413(26)$ & $441(27)$ & .442 & .297 \\
\hline Anemia & $287(14)$ & $358(18)$ & $253(16)$ & $258(16)$ & .158 & .075 \\
\hline Lymph node involvement & $217(11)$ & $233(12)$ & $145(9)$ & $199(12)$ & .104 & .682 \\
\hline Nonspecific infections & $203(10)$ & $255(13)$ & $187(12)$ & $170(10)$ & .102 & .024 \\
\hline Neutropenia & $185(9)$ & $174(9)$ & $139(9)$ & $113(7)$ & .656 & .041 \\
\hline Bacterial infections & $134(7)$ & $153(8)$ & $97(6)$ & $94(6)$ & .510 & .021 \\
\hline HIV infection & $1(0.1)$ & $5(0.2)$ & $2(0.1)$ & $3(0.2)$ & .218 & .999 \\
\hline Hepatitis B virus infection & $8(0.4)$ & $9(0.4)$ & $9(0.6)$ & $6(0.4)$ & .823 & .379 \\
\hline Hepatitis $C$ virus infection & $11(0.6)$ & $12(0.6)$ & $10(0.6)$ & $7(0.4)$ & .852 & .402 \\
\hline Radiation therapy & $62(3)$ & $93(5)$ & $44(3)$ & $96(6)$ & .589 & .109 \\
\hline Fever & $49(2)$ & $67(3)$ & $50(3)$ & $56(3)$ & 191 & .930 \\
\hline Fungal infections & $44(2)$ & $41(2)$ & $31(2)$ & $25(2)$ & .629 & .232 \\
\hline Pancytopenia & $26(1.3)$ & $26(1)$ & $7(0.4)$ & $13(1)$ & .008 & .136 \\
\hline \multicolumn{7}{|c|}{ Chemotherapy agents and level of myelotoxicity } \\
\hline Low risk & $186(9.3)$ & $246(12.2)$ & $146(9.3)$ & $198(12)$ & .001 & .001 \\
\hline Intermediate/High risk & $1,805(90.7)$ & $1,764(87.8)$ & $1,423(90.7)$ & $1,456(88)$ & & \\
\hline \multicolumn{7}{|l|}{ Baseline resource use } \\
\hline All-cause hospitalization & $571(29)$ & $455(22.6)$ & $480(31)$ & $399(24.1)$ & .214 & .290 \\
\hline All-cause ED visits & $192(10)$ & $420(20.9)$ & $171(11)$ & $339(20.5)$ & .291 & .766 \\
\hline
\end{tabular}

Abbreviations: CDI, Charlson-Deyo comorbidity index; ED, emergency department; Post, post-program implementation; Pre, pre-program implementation.

aln the 6-month pre-index period.

bModified CDI: zero weight assigned to malignancy. 
level CSF administration decreased from $71.8 \%$ preimplementation to $70.8 \%$ post-implementation in nonintervention states, an absolute difference of $1 \%$. After adjusting for demographic and FN risk factors, there was a $5.4 \%(95 \% \mathrm{CI},-6.0 \%$ to $-4.7 \% ; \mathrm{P}=.006)$ absolute decrease in CSF administration in intervention versus nonintervention states.

\section{Impact on FN Incidence}

After implementation of the CSF decision support tool, unadjusted FN incidence rates in intervention states changed from $5.0 \%$ to $5.5 \%$, whereas $\mathrm{FN}$ rates in nonintervention states changed from $5.4 \%$ to $4.8 \%$ in the pre- and post-implementation periods, respectively (Table 2). In both intervention and nonintervention states, the unadjusted absolute change in FN rates from the pre- and post-implementation period was $<1 \%$. After adjusting for demographic and patient risk factors, there was essentially no difference in trends in FN rates observed in intervention and nonintervention states $(P=.778)$. Similar results were obtained in sensitivity analyses using a broader claimsbased FN definition, ${ }^{28}$ an even more comprehensive FN definition, ${ }^{28}$ and all-cause inpatient hospitalization or ED admission, suggesting the robustness of our findings. Additionally, subgroup analysis according to CDI score yielded results similar in magnitude and direction to the overall estimate.

\section{Discussion}

CSF administration decreases chemotherapy-induced FN and associated complications. . $^{8,921,30-32}$ CSF prophylaxis is recommended for patients receiving chemotherapy regimens considered to be at high risk of causing $\mathrm{FN}$, or patients receiving regimens with an intermediate risk and who have clinical characteristics believed to place them at higher-than-average risk. ${ }^{18,19,33,34}$ Our results suggest that the risk-appropriateness of CSF administration can be improved by a decision support tool, because there was no evidence of an adverse impact on patient outcomes related to increased FN incidence using several validated claims-based definitions.

Many studies found that a high proportion of patients at low risk for $\mathrm{FN}$ were administered CSF. 12,17,34-36 In an observational, population-based cohort of patients with lung or colorectal cancer, as much as $96 \%$ of overall CSF administration was not in accordance with national guideline recommendations. ${ }^{12}$ Among patients with breast cancer, nearly $50 \%$ of CSF administration in low- to intermediate-risk regimens was not aligned with national guidelines. ${ }^{16}$ Such a pattern of overtreatment in patients for whom there is little expectation of benefit is one of the reasons the NCCN Guidelines for Myeloid Growth Factors and other guidelines are regularly updated. We demonstrated that through implementing an evidence-based decision support tool as part of a prior authorization

Table 2. Change in CSF Use and Incidence of Febrile Neutropenia

\begin{tabular}{|c|c|c|c|c|c|c|}
\hline & \multicolumn{2}{|c|}{$\begin{array}{l}\text { Intervention States } \\
\text { (Subject to the Tool) }\end{array}$} & \multicolumn{2}{|c|}{$\begin{array}{l}\text { Nonintervention States } \\
\text { (Not Subject to the Tool) }\end{array}$} & \multirow{2}{*}{$\begin{array}{c}\text { Intervention vs } \\
\text { Nonintervention States } \\
\begin{array}{c}\text { Adjusted Change From Pre to Post } \\
\%(95 \% \mathrm{Cl})\end{array}\end{array}$} & \multirow[b]{2}{*}{$P$ Value } \\
\hline & $\begin{array}{l}\text { Pre } \\
n(\%)^{\text {a }}\end{array}$ & $\begin{array}{l}\text { Post } \\
\mathrm{n}(\%)^{\mathrm{a}}\end{array}$ & $\begin{array}{l}\text { Pre } \\
\text { n (\%) }\end{array}$ & $\begin{array}{l}\text { Post } \\
\mathrm{n}(\%)^{\mathrm{a}}\end{array}$ & & \\
\hline Total & 1,991 & 2,010 & 1,569 & 1,654 & & \\
\hline CSF administration & $1,491(74.9)$ & $1,376(68.5)$ & $1,126(71.8)$ & $1,171(70.8)$ & $-5.4(-6.0$ to -4.7$)$ & .006 \\
\hline Neutropenia and fever & $100(5.0)$ & $111(5.5)$ & $84(5.4)$ & $80(4.8)$ & $0.2(-0.2$ to 0.3$)$ & .778 \\
\hline \multicolumn{7}{|c|}{ Charlson-Deyo comorbidity score } \\
\hline 0 & $68(3.4)$ & $73(3.6)$ & $56(3.6)$ & $56(3.4)$ & $0.7(-0.5$ to 0.8$)$ & .483 \\
\hline$\geq 1$ & $32(1.6)$ & $38(1.9)$ & $28(1.8)$ & $24(1.5)$ & $0.6(-0.3$ to 0.9$)$ & .786 \\
\hline $\begin{array}{l}\text { Neutropenia and (fever or } \\
\text { infection) }\end{array}$ & $120(6.0)$ & $132(6.6)$ & $90(5.7)$ & $96(5.8)$ & $-0.6(-1.2$ to 0.3$)$ & .703 \\
\hline $\begin{array}{l}\text { Hospitalization or ED visit } \\
\text { for neutropenia or fever } \\
\text { or infection }\end{array}$ & $315(16)$ & $362(18)$ & $263(17)$ & $290(18)$ & $1.9(-1.5$ to 5.5$)$ & .433 \\
\hline $\begin{array}{l}\text { Hospitalization or ED visit } \\
\text { for any cause }\end{array}$ & $734(37)$ & $782(39)$ & $611(39)$ & $673(41)$ & $0.3(-0.1$ to 0.6$)$ & .877 \\
\hline
\end{tabular}

Abbreviations: CSF, colony-stimulating factor; ED, emergency department; Post, post-program implementation; Pre, pre-program implementation. aUnadjusted rates. 
program, a national health plan was able to improve risk-appropriate reduction in CSF administration without an increase in the incidence of FN.

Our findings add to a prior publication in which a similar tool was associated with an even greater reduction in CSF administration among patients with lung cancer with no significant increase in $\mathrm{FN}$ incidence. ${ }^{27}$ Although patients with lung cancer are overwhelmingly older (aged $>65$ years), have significant comorbidities, and are generally treated with palliative chemotherapy, most of the CSF use in patients with breast cancer is among a relatively healthier population receiving chemotherapy with curative intent. Because the clinical implications are vastly different, presenting the impact of the decision support tool in diseasespecific scenarios will be helpful for oncologists.

Although our study did not directly examine expenditures associated with CSF use, there is a reasonable expectation of a reduction in CSF expenditures resulting from a modest reduction in CSF use. A recent report found that an NCCN Guideline-based decision support program reduced chemotherapy cost trends by as much as $20 \% .{ }^{26}$ A 2015 study reported a $\$ 4,782$ USD total cost increase per patient for whom CSF use was not guideline-adherent. ${ }^{16}$ Our finding of a modest reduction in CSF use is not unexpected, because a fairly low proportion of patients in our study sample received low-risk chemotherapy agents $(9 \%-12 \%)$.

To address escalating expenditures and improve care quality, healthcare organizations are increasingly looking to tools and processes to improve adherence to recommended care guidelines. ${ }^{37-39}$ Although processes and tools to improve adherence are important, this study demonstrated that such improvements can be achieved without evidence of increased FN incidence.

\section{Strengths and Limitations}

This study has several strengths. Although no specific ICD-9 diagnosis code exists for FN, we used several previously validated claims-based FN definitions to reduce the risk of misclassification bias. Second, the study used data from a large, geographically diverse patient population drawn from 48 US states. Third, the study design accounted for secular trend changes in CSF administration that may have occurred during the study period. The results, however, are subject to important limitations. Although all patients were undergoing chemotherapy for breast cancer, and although we did examine the use of intermediate/highrisk chemotherapy agents, the specific treatment regimens were not considered in the analysis because our objective was to assess the population-level impact of the decision support tool. Additionally, the limited sample size makes regimen- or risk-level analysis unfeasible. Although high-quality evidence, including randomized controlled trials and widely accepted national guidelines, were used in the development of the decision support program, the level of precision in assessing FN risk based on a planned chemotherapy regimen remains unknown. Certain patient-specific factors (eg, cancer stage), patterns of chemotherapy dose adjustments made by prescribing physicians in response to changes in absolute neutrophil counts or other risk factors, and planned regimen changes during the course of chemotherapy were unavailable in administrative claims data and may have impacted the study results. Such treatment- and patient-specific factors, although important at the individual patient level, should not significantly bias the population-level estimates presented in this study unless they changed differentially and simultaneously with the implementation of the decision support program. Also, because we did not conduct a power analysis, the power with which the difference (or the magnitude of such difference) was tested is unknown. Therefore, this study does not establish the safety of CSF reduction, although our analysis found no significant increase in FN-related patient outcomes. Furthermore, our analysis may have underestimated the incidence of $\mathrm{FN}$, because immunocompromised patients may not exhibit fever. The impact of the CSF decision support tool on other patient outcomes, such as chemotherapy delays or immune recovery, is unknown. Finally, because the database used was from a large employer-sponsored managed care population, the study population was younger and healthier compared with most patients in clinical practice who are $>65$ years of age and covered by Medicare.

\section{Conclusions}

Despite a modest reduction in population-level CSF use, we observed no change in FN rates after implementation of the CSF decision support tool. Our findings suggest that reductions in CSF use can be achieved using decision support tools to reduce prac- 
tice variation and improve adherence to national guideline-recommended care standards. Future studies should investigate the impact of such tools on delays in chemotherapy or immune recovery and the cost-effectiveness of implementations.

\section{Acknowledgments}

Gboyega Adeboyeje, MD, MS, contributed to study design, analysis and interpretation of results. Phil Cochetti and Zhengzheng Jiang, $\mathrm{PhD}$, provided programming support. Cheryl Jones provided writing and editorial support.

\section{References}

1. Berwick DM, Hackbarth AD. Eliminating waste in US health care. JAMA 2012;307:1513-1516.

2. Keehan SP, Sisko AM, Truffer CJ, et al. National health spending projections through 2020: economic recovery and reform drive faster spending growth. Health Aff 2011;30:1594-1605.

3. Porter ME. What is value in health care? N Engl J Med 2010;363:2477-2481.

4. Reilly BM, Evans AT. Much ado about (doing) nothing. Ann Intern Med 2009;150:270-271.

5. Schnipper LE, Meropof NJ, Brock DW. Value and cancer care: toward an equitable future. Clin Cancer Res 2010;16:6004-6008.

6. Bunnell CA, Shulman LN. Will we be able to care for cancer patients in the future? Oncology (Williston Park) 2010;24:1343-1348.

7. Crawford J, Becker PS, Armitage JO, et al. NCCN Clinical Practice Guidelines in Oncology: Myeloid Growth Factors. Version 1.2017. Accessed August 30, 2017. To view the most recent version of these guidelines, visit NCCN.org.

8. Crawford J, Ozer H, Stoller R, et al. Reduction by granulocyte colonystimulating factor of fever and neutropenia induced by chemotherapy in patients with small-cell lung cancer. N Engl J Med 1991;325:164-170.

9. Vogel CL, Wojtukiewicz MZ, Carroll RR, et al. First and subsequent cycle use of pegfilgrastim prevents febrile neutropenia in patients with breast cancer: a multicenter, double-blind, placebo-controlled phase III study. J Clin Oncol 2005;23:1178-1184.

10. Krzemieniecki K, Sevelda P, Erdkamp F, et al. Neutropenia management and granulocyte colony-stimulating factor use in patients with solid tumours receiving myelotoxic chemotherapy-findings from clinical practice. Support Care Cancer 2014;22:667-677.

11. Morrison VA, Wong M, Hershman D, et al. Observational study of the prevalence of febrile neutropenia in patients who received filgrastim or pegfilgrastim associated with 3-4 week chemotherapy regimens in community oncology practices. J Manag Care Pharm 2007;13:337-348.

12. Potosky AL, Malin JL, Kim B, et al. Use of colony-stimulating factors with chemotherapy: opportunities for cost savings and improved outcomes. J Natl Cancer Inst 2011;103:979-982.

13. Scott SD, Chrischilles EA, Link BK, et al. Days of prophylactic filgrastim use to reduce febrile neutropenia in patients with non-Hodgkin's lymphoma treated with chemotherapy. J Manag Care Pharm 2003;9:15-21.

14. von Minckwitz G, Schwenkglenks M, Skacel T, et al. Febrile neutropenia and related complications in breast cancer patients receiving pegfilgrastim primary prophylaxis versus current practice neutropenia management: results from an integrated analysis. Eur J Cancer 2009;45:608-617.

15. Weycker D, Hackbarth AD, Edelsberg J, et al. Are shorter courses of filgrastim prophylaxis associated with increased risk of hospitalization? Ann Pharmacother 2006;40:402-407.

16. Ramsey SD, Fedorenko $C$, Chauhan $R$, et al. Baseline estimates of adherence to American Society of Clinical Oncology/American Board of Internal Medicine Choosing Wisely Initiative among patients with cancer enrolled with a large regional commercial health insurer. J Oncol Pract 2015;11:338344 .

17. Ramsey SD, McCune JS, Blough DK, et al. Colony-stimulating factor prescribing patterns in patients receiving chemotherapy for cancer. Am J Manag Care 2010;16:678-686.

18. Schnipper LE, Smith TJ, Raghavan D, et al. American Society of Clinical Oncology identifies five key opportunities to improve care and reduce costs: the top five list for oncology. J Clin Oncol 2012;30:1715-1724.

19. Smith TJ, Bohlke K, Lyman GH, et al. Recommendations for the use of WBC growth factors: American Society of Clinical Oncology clinical practice guideline update. J Clin Oncol 2015;33:3199-3212.
20. Rosenberg A, Agiro A, Gottlieb M, et al. Early trends among seven recommendations from the Choosing Wisely campaign. JAMA Intern Med 2015;175:1913-1920.

21. Weycker D, Li X, Barron R, et al. Importance of risk factors for febrile neutropenia among patients receiving chemotherapy regimens not classified as high-risk in guidelines for myeloid growth factor use. J Natl Compr Canc Netw 2015;13:979-986.

22. Lyman GH, Dale DC, Legg JC, et al. Assessing patient's risk of febrile neutropenia: is there a correlation between physician-assessed risk and model-predicted risk? Cancer Med 2015;4:1153-1160.

23. Bero LA, Grilli R, Grimshaw JM, et al. Closing the gap between research and practice: an overview of systematic reviews of interventions to promote the implementation of research findings. BMJ 1998;317:465-468.

24. Oxman AD, Thomson MA, Davis DA, Haynes RB. No magic bullets: a systematic review of 102 trials of interventions to improve professional practice. CMAJ 1995;153:1423-1431.

25. Weingarten SR, Henning JM, Badamgarav E, et al. Interventions used in disease management programmes for patients with chronic illness-which ones work? Meta-analysis of published reports. BMJ 2002;325:925.

26. Newcomer LN, Weininger R, Carlson RW. Transforming prior authorization to decision support. J Oncol Pract 2017;13:e57-61.

27. Adeboyeje G, Agiro A, Malin J, et al. Reducing overuse of colony-stimulating factors in patients with lung cancer receiving chemotherapy: evidence from a decision support-enabled program. J Oncol Pract 2017;13:e337-345.

28. Weycker D, Sofrygin O, Seefeld K, et al. Technical evaluation of methods for identifying chemotherapy-induced febrile neutropenia in healthcare claims databases. BMC Health Serv Res 2013;13:60.

29. Deyo RA, Cherkin DC, Ciol MA. Adapting a clinical comorbidity index for use with ICD-9-CM administrative databases. J Clin Epidemiol 1992;45:613-619.

30. Clark OA, Lyman GH, Castro AA, et al. Colony-stimulating factors for chemotherapy-induced febrile neutropenia: a meta-analysis of randomized controlled trials. J Clin Oncol 2005;23:4198-4214.

31. Tan H, Tomic K, Daniel G, et al. Evaluating the risk of hospitalization with G-CSF use in real-world oncology practice [abstract]. J Clin Oncol 2009;27(Suppl):Abstract 6626.

32. Trillet-Lenoir V, Green J, Manegold C, et al. Recombinant granulocytecolony stimulating factor reduces the infectious complications of cytotoxic chemotherapy. Eur J Cancer 1993;29A:319-324.

33. Agiro $\mathrm{A}, \mathrm{Ma} \mathrm{Q}$, Acheson $\mathrm{AK}$, et al. Risk of neutropenia-related hospitalization in patients receiving colony-stimulating factors with chemotherapy for breast cancer. J Clin Oncol 2016;34:3872-3879.

34. Smith TJ, Hillner BE. Bending the curve in cancer care. N Engl J Med 2011;364:2060-2065

35. Bennett CL, Smith TJ, Weeks JC, et al. Use of hematopoietic colonystimulating factors: the American Society of Clinical Oncology survey. J Clin Oncol 1996;14:2511-2520.

36. Bennett CL, Weeks JA, Somerfield MR, et al. Use hematopoietic colonystimulating factors: comparison of the 1994 and 1997 American Society of Clinical Oncology surveys regarding ASCO clinical practice guidelines. J Clin Oncol 1999;17:3676-3681.

37. Feinberg BA, Milligan S, Cooper J, et al. Third-party validation of observed savings from an oncology pathways program. Am J Manag Care 2013;19:SP153-157.

38. Gesme DH, Wiseman M. Strategic use of clinical pathways. J Oncol Pract 2011;7:54-56.

39. Rotter T, Kinsman L, James E, et al. Clinical pathways: effects on professional practice, patient outcomes, length of stay and hospital costs. Cochrane Database Syst Rev 2010;CD006632. 